\title{
Towards the Design of a Kids' Music Organizer
}

\author{
Manuela Hutter \\ Vegetarierbund Deutschland \\ Geschaftsstelle, Blumenstr. 3 \\ Hannover, Austria \\ +5113632050 \\ manuela.hutter@gmx.at
}

\author{
Sally Jo Cunningham \\ Computer Science Department \\ University of Waikato \\ Hamilton, New Zealand \\ +6479394402 \\ sallyjo@cs.waikato.ac.nz
}

\begin{abstract}
In this paper, we investigate how young children aged 2 to 5 interact with music and their family's music collections. By going into their homes, interviewing them and their parents and observing the children performing a range of music-related tasks, we explore the way that pre-school children select, interact with, and organize music. Additionally, drawing tasks were included in the visits to engage the children and allow them to demonstrate their thoughts in a concrete manner. Insights into the children's' music behaviours suggest design features for a music organizer/ player for very young children.
\end{abstract}

\section{Categories and Subject Descriptors}

D.2.2 [Design Tools and Techniques]: User interfaces; H.5.2 [User Interfaces]: User-centered design

\section{General Terms}

Design

\section{Keywords}

Children, qualitative research, user-centered design, requirements elicitation

\section{INTRODUCTION}

Children encounter and use computer-based technologies in their daily lives, and are emerging as a significant user population for many domains formerly reserved for adults. Children's abilities and interests change rapidly as they grow; truly, "age matters" [1] when designing for children, and a pre-school (and pre-literate) child will experience difficulty in operating a system designed for older children. Clearly, children require special software and hardware, designed to their requirements [7]. Interface and interaction design researchers are developing an understanding of the techniques required to create more effective and usable technologies for children [3], and of how to apply ethnographic techniques to better understand children's' motivations and behaviours in regards to technology [7].

A number of music-related systems aimed at children are described in the research literature. They are primarily focused on supporting children in creating music (eg, [6], [5]), often in the context of formal music education (eg, [4]). MIR research Permission to make digital or hard copies of all or part of this work for personal or classroom use is granted without fee provided that copies are not made or distributed for profit or commercial advantage, and that copies bear this notice and the full citation on the first page. To copy otherwise, to republish, to post on servers or to redistribute to lists, requires prior specific permission and/or a fee. CHINZ 2008, July 2, 2008, Wellington, New Zealand (C) 2008 ACM 978-1-60558-467-6/07/0008...\$5.00 attention has not yet turned to the task of supporting children in playing, browsing, searching, and organizing collections of existing music - creating a child-centric music player and organizer. This paper is a first step towards the design of such a system: we present initial design insights that emerge from a qualitative, ethnographic study of pre-school children. Our aim is to support the requirements elicitation stage of design by developing a rich picture of pre-school music behaviours, in regards to existing, commercially produced music.

\section{EXISTING SYSTEMS}

Although there is a broad palette of music player / organizer software available for the average adult user, we were not able to find an application designed for the special needs of little children. Physical media devices are available that are aimed at children; however, most are designed for children over 5 years old.

The Max-Joy audio player from German maker Maxfield1 is intended for children aged between six and twelve. Maxfield claims that several features are specifically designed with youngsters in mind: a volume limit of $60 \mathrm{~dB}$, larger than normal operating buttons, over the ear rather than ear-bud headphones and a rugged, rubberized case. The interface is claimed to be easy to use, but the display is primarily text-a huge obstacle for preor barely- literate young children. The interface does not provide any special features to increase the fun factor.

Fisher-Price produces the Digital Song and Story Player2, for children aged three and upwards. The device comes with tiny volume-restricted headphones, and the buttons are even larger than the ones of the MAX-JOY player. An LCD screen with icons helps kids recognize and choose songs and stories by themselves. Parentally approved songs for the player are sold at an iTunes-style online store.

SEGA's i-Dog3 is not a player as such; it is more a moving, dogshaped speaker that moves to the beat of the music - both plugged in or just near i-Dog. It is also able to communicate 'moods' by multicolored LEDs on its face. Patting the head or flicking the tail can influence the moods.

While no published design rationales are available for these products, it can be seen that the manufacturers carefully consider safety features (for example, volume limits) and sturdiness in designing music players. The cases are all colourful and attractive; children do not appreciate stylish, minimalist black/white players. Beyond these characteristics, there is little in the way of functionality that is tailored to child-specific behaviours.

\section{METHODOLOGY}

This study used two methods for exploring children's' music behavior: interviews (Section 3.2) and drawing tasks (Section 
3.3). Both were designed to elicit information on the following areas:

- Musical preferences: likes and dislikes

- Parent's influence: how active the children are in choosing/playing music, and how much support is offered by the parents

- Frequency of music consumption

- Environment: where the children listen to/play music, and what devices they use

- Organization: how the children's music organized

- Visual elements: how important are images associated with the music

\subsection{Participants}

Participants of the study were children and parents from three families: a total of seven children, aged $2 \frac{1}{2}$ to 7 years old. Five of the children were female, and two male. Five of the parents were present at the interview sessions, and were also interviewed (three mothers, two fathers). While seven child and five adult participants constitutes a relatively small sample size, this is appropriate for qualitative studies that include significant opportunity to discuss and interact with the participants. The aim here is to develop a rich understanding of specific music behaviors rather than to produce a large, statistically generalizable set of data. The children and parents from the three families were interviewed in four sessions, and the sessions lasted from two to four hours each.

\subsection{Session Organization}

Children cannot be interviewed with a rigidly structured protocol; they have their own questions to ask, frequently change the subject of discussion, switch rapidly from talking to singing to playing with a nearby toy, and suddenly become shy and hide behind a parent.

Both researchers attended the family sessions. Interviews took place within the family home, so that the children would feel more comfortable and so that the researchers could see the children's' music behavior in its normal context. This approach is frequently used, as a means of eliciting 'normal' behavior [3]. At least one parent was present during the entire session, to interpret the children's sometimes difficult to understand responses and to answer questions directed to the parents. The parents also worked to bring the focus back on to music when the children became distracted.

At the beginning of each session, the researches spent about 15 minutes chatting to the children and their parents, to allow the children to overcome any initial shyness. The sessions began with moved on to drawing tasks (Section 3.4), and then concluded with the remainder of the child-directed questions. The combination of drawing tasks and interview worked well, since being allowed to draw was in effect a small reward that encouraged the children then answer more questions. At the end of the session the parents were asked a further set of questions (Section 3.3), and the researchers discussed the session with the parents to clear up any uncertainties about the children's responses.

Our approach was to focus on listening to what the children themselves have to tell. To this end, both researchers attended each interview session, one working with the child and the second researcher sitting off to the side taking notes on the dialog. Since pre-school children are too young to clearly verbally articulate their feelings, notes were also taken about the children's' emotional displays and physical actions [2].

\subsection{Interviews}

Separate sets of questions were directed to the children and to their parents. The interviews were semi-structured; participants were free to explore tangents suggested during the session.

\section{Questions for children:}

- Do you know the names of people who make music?

- Do you play any instruments?

- Can you find me some music?

- Can you play that music?

- What is your favorite music?

- Some other music you like?

- Is that your music, or your parents' music?

- Where does the music play?

- Are there other places where the music plays?

- What instruments do you like?

- What does that instrument look like?

- How is that instrument played?

- $\quad$ Do you like the cover [of your favorite CD]?

Questions for parents:

- What was the child's first contact with music?

- How do you use music with your child? (background noise / distraction / education / cheer-up / lullaby / getting the child to do something)

- What music do you like? Same / different than your partner?

- How important is music for you?

- Do you encourage the child to listen to music? In what way?

- What type of music do you like?

- Does the child actively ask for music? 
- Does the child actively use music for a certain purpose? ("workout" / distraction / lullaby)

- What makes music interesting for your child? (slow/fast songs, funny lyrics, videos)

- Is there a distinction in your household between 'kids' music and grown up music? Do you play special 'kids' music?

- Where is the music that the child listens to / likes? Where is your music?

- Is there a special organization for the music?

- Does the child get bored with certain songs / instruments?

- Are you happy with the music that your child likes?

\subsection{Drawing tasks}

Drawing tasks were included to explore the possibility of children producing their own visual interpretations of music, to be used in the interface of a personal music /player organizer. The drawing tasks were intended to be understandable by both the parents and the children. For the parents, the task is described textually; for the children, an icon is provided to remind them of the focus of the drawing (although, of course, the children also required additional verbal reminders of the task as they drew). Each task was completed on a separate sheet of paper, with the sheet including a pre-printed text and icon description of the task (Figure 1).

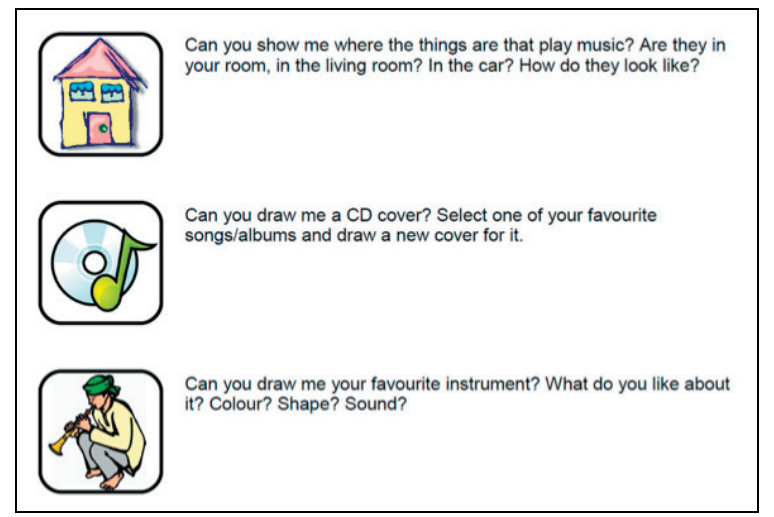

Figure 1. Descriptions printed on drawing tasks sheets.

\section{MUSIC BEHAVIORS}

In this section we summarize the behaviours observed in our interview sessions with the children and their parents.

\subsection{Tasks}

The children that we interviewed all liked playing an instrument, more or less seriously. One three-year-old girl, part of a very musical family, has been learning the violin for one year. Another girl has her own small guitar/ukulele that she loves to strum while listening to rock songs ("her guitar is one of the few musical instruments she doesn't get bored with"). Others have keyboards that were specifically designed for little children, drums, shakers or whistles. Moreover, they have toys (puppets, stuffed octopuses or birds) that play music by pressing or squeezing parts of them.
The instruments that they like listening to are mostly the same ones as the ones they play, with the violin and the guitar being mentioned the most, but shakers (or things with the same effect, like a bag of bulbs) are actually played most frequently.

The music that kids listen to can be categorized in two major groups: music for grown-ups and music specifically created for preschool children. 'Grown-up' music is strongly influenced by the parents' taste and elements of everyday life (church, choir); this is commercially produced music that the parents themselves also listen to on CDROM, music video TV channels, cassette tapes, and so forth. 'Kids music' is music specifically created with children as the target audience, and it consists of music that the parents listened to when they themselves were children; songs that the children encounter at crèche ("she came home and was telling me, they did Bob the Builder. She likes to tell us new things"), kindergarten, or special music classes for children (e.g. Mainly Music on Mondays); and music appearing on children's TV programs and movies.

The interviews with the parents indicate that the partners may not share the same tastes in 'grown-up' music: for this limited set of participants, the mothers prefer more quiet and relaxing music than the fathers. One mother explained that she is often quite stressed out by household and child-care work, and so would use music as a tool to relax. The children tend to prefer the music of the fathers, especially if it is Rock n' Roll or Blues where there is a rhythm that they can dance and bounce to. Examples are Glen Miller, The Beatles and David Bowie. The music that their mothers are listening to often lacks this strong rhythm and is seen by the children as being boring and uninteresting.

The most favored 'kids music' that the children in this study are listening to include Echo Fred (New Zealand children's music), The Wiggles and Hi-5 (both Australian 'kids music' bands). These groups all have songs that encourage physical activity in the children by using a strong beat that invites clapping or dancing; having clear, understandable and kids related lyrics ("she also reacts more to artists who sing the words clearly"); and by being visually distinctive and appealing (e.g. wearing shirts in the same color at every concert).

Often favorite songs had an association with an event or person special to the child, or to a family in-joke. For example, one girl liked the song 'Windy Wellington', as the song is about Wellington, a city she has been to herself, so "the words have something to do with an experience she's been a part of." Another girl especially liked the music by 'Uncle Chris', a New Zealand artist she personally knew and could think of while listening to the songs. One father had made some songs interesting to his daughter by changing the lyrics: "if we change the words to something funny, she starts to like the whole song as music and words ... we got her interested in the song [Eight Days A Week, by the Beatles] by singing 'doggie doggie' instead of 'hold me love me'".

With both 'grown-up' and 'kids music', the opportunity for physical involvement enhances the children's enjoyment of the songs. The kids especially love songs "with lots of hands actions", like the Bunny Hop song, or 'einsy beansy spider'.

\subsection{Purpose of Music}

Parents and other caregivers often have an effect that they are trying to elicit in the children when they choose music to play for the kids. During the day, music may either serve as a background 
noise (passive listening) or just another way of keeping the kids busy, by encouraging them to dance and enjoy themselves (active involvement). Music can also be used as a distraction or to calm them down; for example nursery rhymes can be used to make children forget about why they are crying, or easy-listening music may put them to sleep.

Music may also have an overt educational goal. In this study parents reported selecting music to be used to practice music and dancing, to teach religious concepts, to learn colors and counting or to introduce a second language (Maori). But the song has to be good as music, as well as having an educational component; since the kids are distracted very easily, the song has to be interesting enough to get their attention ("the concept of the song has to engage her").

An interesting aspect of music is that it can encourage the kids to perform a task that is not normally related to music. A father explains, for example, that he can make his daughter tidy up her toys by playing the Blue's Clues clean-up song.

\subsection{Music Players and Their Locations}

Most of the music in the homes of the interviewed kids is played from CD players. The most important player is located in the living room, where all the action takes place during the day and where the kids have enough space to move and dance to the music, but are as well close to the parent(s) looking after them. The second-most important place to listen to music seems to be the car; music is a good distraction for children impatient with a lengthy trip (say, over 5 minutes). Most of the kids have their own CD player in their room, but they don't seem to spend a lot of time in these rooms during the day, so it is mainly used in the evenings to have some music or a story playing while falling asleep.

A lot of music is listened to in connection with a visual representation; videos and DVD's are very popular for that purpose. Three of the kids already have experience with the computer. They knew how to navigate ("you move the mouse") and they were very secure in the way they found their way around. The main use of the computer, however, was to play games rather than to listen to music.

\subsection{Song Organization and Selection}

All the kids that we worked with had their own CD's (and DVD's). Most of the time, the parents did not clearly separate the kids stuff from their own - the 'grown ups' and kids CDs/DVDs tended to be in the same pile, near the media player. However, the parents tried to put the children's music to the front of the pile in order to make it easier to see and grab ("all her stuff is out, ours is in the video cabinet. It's best to have her stuff out in the open, then she can access It.").

The children show very good spatial memory, and they do a great job in locations of CDs/DVDs and in remembering names and titles. When watching a Queen DVD for example, one child was able to name the song title just by seeing an album cover image that was shown shortly before the song started. In terms of the physical location of the CD's, the children are not only able to point the vague location of their music ("mine are down there"), they unhesitatingly go to a pile of CD's and point at the one they want to hear, just by knowing how the small part at the side of the CD looks like ("she said: 'it's over in the corner', and there it was"). When asked how she could find her favorite $C D$, one girl said "you need a map in your head". None of the adults present had expected this level of abstraction in a 3-year-old child. Moreover, they seem to remember songs by linking them to some other things they know, for example people ("the David Bowie one"), animals ("the doggy song"), instruments ("this one has the saxophone"), other things (pointing at her trousers: "Jean Jeannie"), or even moods ("the funny one", "it's so silly").

How actively the children choose the music to play varies, and depends on factors like the child's age, parents, devices and moods. The older the children, the more actively they want to be involved in the decision process. The $2 \frac{1}{2}$ year old child did not actively select music and ask for playing it, but did communicate (by (not) dancing, laughing) if she liked a song or not. Depending on their mood and what they are working with at the moment, older children would ask for the music they want to listen to ("she likes whatever is being played", "she is actively requesting music"), and they explicitly say if they do not like it ("I don't want to listen to this"), and sometimes also say why (about hard rock: "that's too loud"). If the children like the music, they often don't say it in words (even when they are a bit older). During our studies, they were dancing, jigging up and down, standing up and getting closer to the music player, playing visible and invisible instruments (at one point sack of daffodil bulbs was functioning as an instrument, too). Some kids would grab the CD or DVD themselves and play it, others don't feel like doing that ("mummy do it"), or they are not allowed to, often because they broke some devices earlier or because the parents think that the kids are too young ("She is not allowed to input CD's or push the buttons yet").

\subsection{Frequency and Duration of Music Consumption}

Music plays an important role in the lives of the kids who participated in our study. They all listened to music on a regular basis, and were encouraged to do so by their parents and other caregivers. There appear to be three modes for listening to music: passive listening, active listening/interacting and fadeout mode.

During the day, the children may just passively listen to music that is played by their parents as a background while they are doing something else (e.g. drawing, playing). In this case, typically an entire $\mathrm{CD}$ would just be left to play and the child would only focus on the music if a song comes on that the child especially likes (and so draws the attention of the kid) or dislikes (and which would make the child want to remove/change the CD). If the child actively selects the music to play, their main activity is to listen and dance to it. In this case, the children are usually very easily distracted; they might listen to one song or even just a part of the song.

All children like repetition, and music is not an exception. If a child is allowed to work the media player, then she/he will often listen to the same song over and over again. If they listen to a few songs in a row, it is very likely that they will be distracted by another activity after three or four songs-so it is unlikely that the children will repeat groups of two or more songs. Listening actively to the complete $\mathrm{CD}$ is unlikely; the duration is well past their attention span.

Some of the kids had their own CD player in their bedroom, and they would use it at bedtime to listen to either music or stories until they fall asleep ("fadeout mode". Then the CD stops eventually (or the parents tiptoe into the room to stop it). For night use, a fade-out/timer function on a child's CD player might 
be helpful, by reducing the chance that a song might disturb the child's sleep.

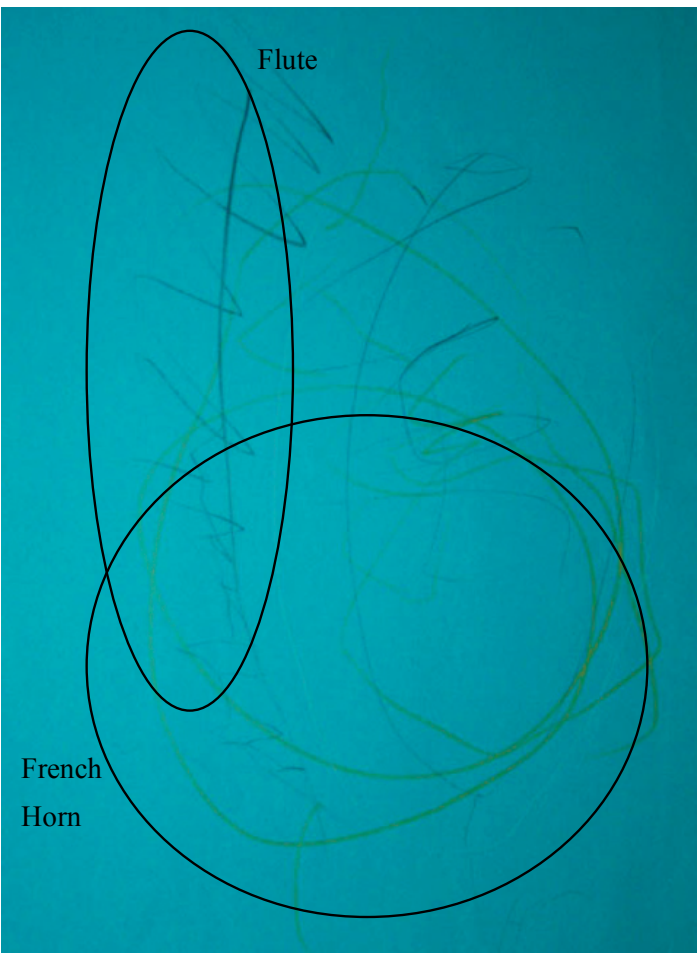

Figure 2. Child's CD cover for Peter and the Wolf.

\subsection{What Does Music Look Like?}

The interviews with the children interspersed questions and drawing tasks, where the drawings were intended to elicit a sense of the visual elements that the children associate with their music. The children were asked to draw a CD cover for a specific song or song collection, and to draw the instruments that they found most interesting. The children seemed to enjoy drawing, but generally needed a bit of prompting (usually from the parent) to identify the images to include. Figure 2 is a suggested new cover for a Peter and the Wolf $\mathrm{CD}$. The child drew quickly and confidently, including the instruments that she most strongly associated with the 'Peter' and 'Wolf' sounds (a flute and French horn). The level of detail is typical for the drawings produced by the children.

\section{DESIGN IMPLICATIONS}

The interviews and observations with the children and their parents raised a number of issues that should be addressed when designing a music player for preschool children.

The first question to clarify is who the users are going to be. As we learned from the interviews, the children are selecting the music when they are actively listening and dancing to the music. When they are listening passively or if they are put to sleep, it is mostly the parents who start the playback. Now, should the new music player be a suitable music player for both preschoolers and parents of young children? In that case, the interface would need minimal-ideally, no- text, suggesting a $100 \%$ graphics based interface.
Or could it be that with the aid of the new software, the children can do more things themselves? The children participating in our study were frequently cautioned against touching the expensive players in the household, in part for fear that something might break. A more rugged design - shockproof, waterproof, crayon proof - would free children to use the device without requiring adult mediation.

Another question to ask is if a music player on a standard computer is the appropriate device for the youngsters. We have seen that they listen to music mostly in the living room and the car, and only sometimes in their bedroom. Again, this restriction of their music to a relatively few places likely occurs because the current music players are relatively immobile. A portable player, sized for smaller hands and bodies, is suggested.

Children tend to be distracted very easily, and once they move on to a new activity they might not think of turning off the music that they don't really want to listen to any more. The device might therefore have a mode that enables the user to only play music as long as the device is held in the hand. As soon as the child gets distracted and puts away the device, the music stops.

For both a physical device and music player software, the repeat function should play a central role in the design. It should be easy (perhaps even the default?) to repeat a song; this function should not be hidden in a sub-menu. Children also tend to become fascinated with particular sections or sounds in a song, and sing those back to their parents over and over. Repeating parts of a song might also be a function that children would like to have - if it is easy enough for them to use.

Children enjoy experiencing music visually, as well as aurally; they watch music videos, and most children's movies and TV shows have a strong soundtrack or other music component. A display for any accompanying video would likely be greatly enjoyed, and if no video is available visualization could be included (preferably including a human or animal rather than an abstract pattern).

A playlist construction function would clearly be useful-it would allow the children to more actively manipulate their collections and control the songs they listen to-but would require careful design. Songs would have to be represented by graphics rather than text. Given the idiosyncratic way in which the children remember and reference songs (for example by instrument, artist, or association with family events), each song icon would have to be tailored by the child or the parents. One idea that occurred prior to the first interview was to allow the children to draw their own icons; this idea was discarded after we realized that the children's art was not easy to interpret (even by the child, at a later date). A better plan would be to provide a library of icons for the child to select from, and perhaps to tailor in simple ways (for example, by altering the colors in an icon).

Scattered throughout the children's' homes were objects that the children had created-drawings stuck to the refrigerators, playdough sculptures, Lego constructions, and so forth. The children obviously enjoyed creating these pieces, and were encouraged by their parents to give them as gifts; one participant began the interview by proudly giving each of the researchers a miniature rock garden that she had created in crèche (Figure 3). Given that creation of gift objects is such a frequent and enjoyable activity, a music organizer that would allow children to create musical gifts would be appreciated-for example, that would aid 
the child in creating a music CD of her favourite songs, complete with a personally designed $\mathrm{CD}$ cover.

\section{ACKNOWLEDGMENTS}

Our thanks to the parents and the children who participated in this study, who so gave so much of their time and energy to the home visits and interviews.

\section{REFERENCES}

[1] Druin, A. "Age Matters". SIGCHI Bulletin, September/October 2002, p. 5.

[2] Hanna, L., Risden, K., and Alexander, K. "Guidelines for usability testing with children”. Interactions 4(9), 1997, 914.

[3] Jensen, J.J., and Skov, M.B. "A review of research methods in children's technology design". Proceedings of Interaction Design and Children, 2005, 80 - 87.
[4] McKinnon, I. "Children's music journey: the development of an interactive software solution for early childhood music education". Computers in Entertainment 3(4), 2005, 1-10.

[5] Pachet, F., Addessi, A.R. "When children reflect on their own playing style: experiments with continuator and children”. Computers in Entertainment 2(1), 2004, 14.

[6] Ventura, D., and Mase, K. "Duet Musical Companion: improvisational interfaces for children". Proceedings of the 2003 Conference on New Interfaces for Musical Expression, 2003, 91-94.

[7] Wyeth, P. "Ethnography in the kindergarten: examining children's play experiences". Proceedings of the SIGCHI Conference on Human Factors in Computing Systems, 2006, $1225-1228$ 